\title{
Fluoroform $\left(\mathrm{CHF}_{3}\right)$
}

\section{ShivaKumar Kyasa}

Department of Chemistry, University of Nebraska-Lincoln, Lincoln, NE 68588-0304, USA shiva@huskers.unl.edu

Published online: 11.06 .2015

DOI: 10.1055/s-0034-1380924; Art ID: st-2015-v0519-v
ShivaKumar Kyasa was born in Telangana state, India, in 1978. After completing a B.Sc. (chemistry, biology) and a M.Sc. (medicinal chemistry) from Osmania University, he worked at Dr. Reddy's Laboratories, Ltd., Hyderabad, India. He is currently pursuing a Ph.D. in chemistry at the University of Nebraska-Lincoln, USA under the supervision of Prof. Patrick H. Dussault. His research focuses on $\mathrm{C}-\mathrm{O}$ bond formation and synthesis of functionalized ethers using peroxide oxygen as an electrophile.

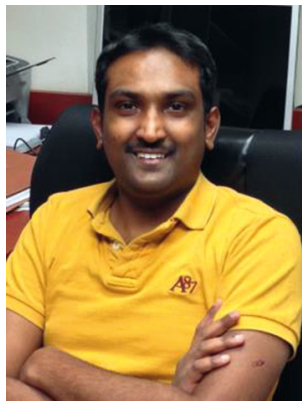

\section{Introduction}

Fluoroform, which is generated in 20 kilotons/year as a side product of Teflon manufacture, ${ }^{1,2}$ is a low-boiling $\left(-82{ }^{\circ} \mathrm{C}\right)$, non-toxic and non-ozone-depleting gas. ${ }^{1,3}$ However, fluoroform is a potent greenhouse agent and there is great interest in methods for use of the gas as a synthetic reagent. The direct use of trifluoromethyl anion as a nucleophile has been challenging due to facile $\alpha$-elimination to fluoride and difluorocarbene (Scheme 1). The activation of $\mathrm{Me}_{3} \mathrm{SiCF}_{3}$ (often described as the Ruppert-Prakash reagent) with Lewis bases (most commonly catalytic fluoride) to afford pentavalent silicon species as nucleophiles has enabled trifluoromethylation of a number of electrophiles. ${ }^{4}$ The trifluoromethyl group has great importance in medicinal, agrochemical and materials science. ${ }^{5}$ This spotlight describes recently reported methods for tri- and difluoromethylation based upon fluoroform.

$$
\stackrel{\ominus}{\mathrm{CF}_{3}} \longrightarrow \ddot{\mathrm{C}}_{2}+\stackrel{\ominus}{\mathrm{F}}
$$

Scheme $1 \alpha$-Elimination of trifluoromethyl anion to difluorocarbene and fluoride.

Table 1 Use of Fluoroform $\left(\mathrm{CHF}_{3}\right)$

(A) Prakash and co-workers have demonstrated successful deprotonation of $\mathrm{CHF}_{3}$ in ethereal solvents using KHMDS; the method was applied to the synthesis of trialkyl trifluoromethyl silane, trifluoromethyl fluoroborate and trifluoromethane sulfonic acid (Eq 1-3). Nucleophilic trifluoromethylation was also demonstrated for 1,2additions to non-enolizable ketones and esters, chalcones, formate esters, and displacement of benzyl bromide and methyl benzoate was also demonstrated to proceed in moderate yields (illustrated for non-enolizable carbonyl compounds, Eq 4). Attempts to apply sodiated and lithiated bases were unsuccessful, revealing that potassium is essential for stable : $\mathrm{CF}_{3}$ generation. ${ }^{1}$

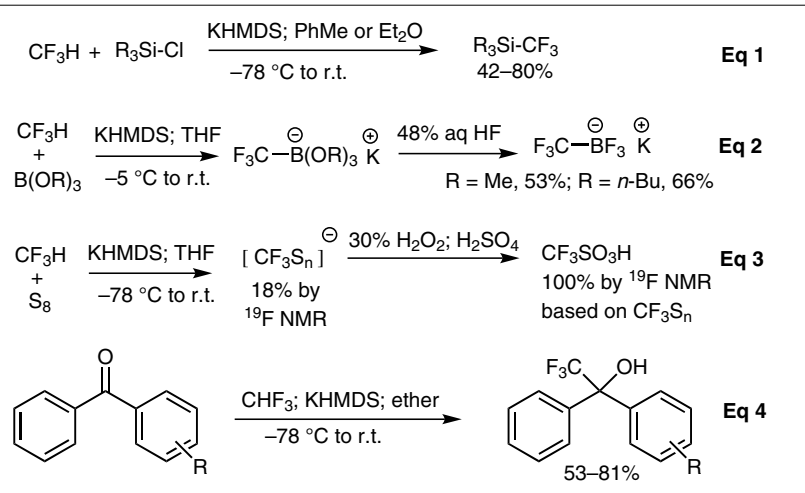

(B) Dolbier and co-workers utilized $\mathrm{CHF}_{3}$ as a difluorocarbene source, preparing difluoromethyl ethers and thioethers from the corresponding phenols and thiophenols in the presence of $\mathrm{KOH}^{6}$ The method, which involves biphasic conditions and can be conducted at atmospheric pressure, furnishes moderate to good yields of ethers.

(C) Mikami and co-workers discovered that lithium enolates react with $\mathrm{CF}_{3} \mathrm{H}$ to achieve $\alpha$-difluoromethylation via displacement of a $\mathrm{C}-\mathrm{F}$ bond; the method has been applied thus far only to lactone and lactam enolates.

Method-A: $\mathrm{CHF}_{3}$ (8 equiv); $\mathrm{KOH}$ (10 equiv); $\mathrm{H}_{2} \mathrm{O}$-dioxane, $50^{\circ} \mathrm{C}, 4 \mathrm{~h}$ Method-B: $\mathbf{C H F}_{3}$ (14.2 equiv); $\mathrm{KOH}$ (15 equiv); $\mathrm{H}_{2} \mathrm{O}-\mathrm{MeCN}$, r.t., $2 \mathrm{~h}$

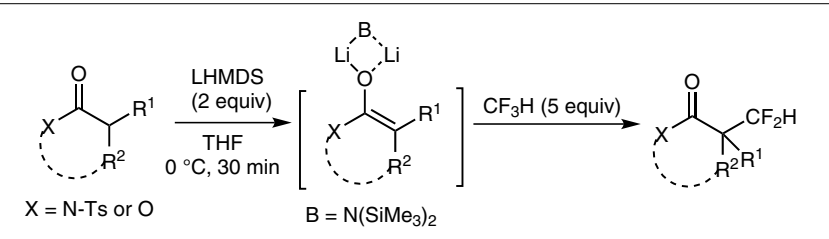


(D) The Shibata group explored activation of fluoroform with organic super bases and demonstrated that P4-t-Bu can be used to generate a stable $\mathrm{CF}_{3}$ anion at $-30^{\circ} \mathrm{C}$ in THF solvent; under these plied to the trifluoromethylation of aromatic carbonyl compounds. ${ }^{5}$ conditions, the anion was stable at up to $-10{ }^{\circ} \mathrm{C}$. The anion was ap-



(E) Nucleophilic trifluoromethylation using $\mathrm{CHF}_{3}$ in the presence of $\mathrm{P} 4-\mathrm{t}$-Bu has also been applied to reactions with acid chlorides, esters, carbon dioxide, and epoxides. ${ }^{8}$ Acid chlorides react to provide mixtures of trifluoromethyl ketones and $3^{\circ}$ alcohols (Eq 1 ). In contrast, methyl benzoate reacted to give only phenyl trifluoromethyl ketone (Eq 2). The trifluoromethyl anion reacts with carbon dioxide to produce trifluoroacetic acid (Eq 3). Curiously, reaction with terminal epoxides occurs at the more hindered carbon to give a $3^{\circ}$ alcohol (Eq 4).

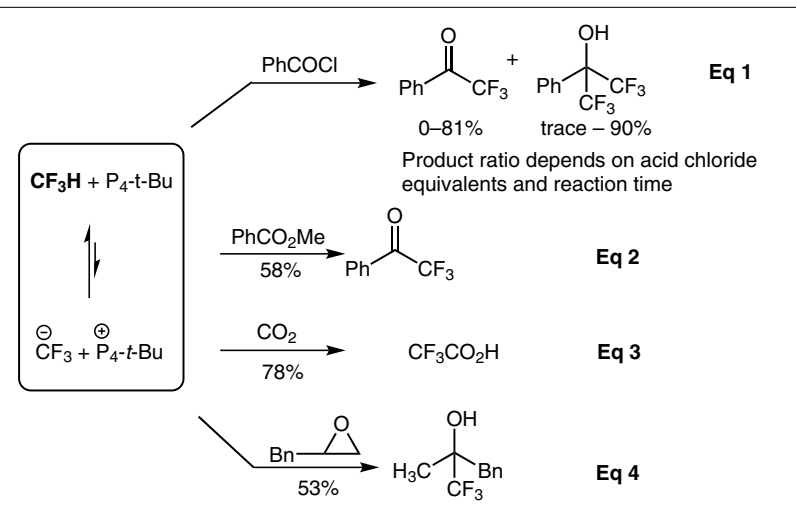

(F) Grushin and co-workers synthesized $\mathrm{CuCF}_{3}$ by cupration of fluoroform using $\mathrm{CuCl}$ and $t$-BuOK in DMF. ${ }^{3 \mathrm{a}}$ The reagent was applied to trifluoromethylation of aryl and heteroaryl halides, ${ }^{3 \mathrm{~b}}$ aryl boronates, ${ }^{9}$ and $\alpha$-halo ketones. ${ }^{10}$

(G) Potash and Rozen demonstrated the formation of trifluoromethyl thioethers through reaction of $\mathrm{CuCF}_{3}$ with alkyl, aryl, and heteroaryl thiocyanates. ${ }^{2}$ Similarly, fluoroform-derived $\mathrm{CuCF}_{3}$ was applied to the synthesis of trifluoromethyl selenides from selenocyanates. ${ }^{11}$

\section{References}

(1) Prakash, G. K. S.; Jog, P. V.; Batamack, P. T. D.; Olah, G. A. Science 2012, 338, 1324.

(2) Potash, S.; Rozen, S. J. Fluorine Chem. 2014, 168, 173.

(3) (a) Zanardi, A.; Novikov, M. A.; Martin, E.; Benet-Buchholz, J.; Grushin, V. V. J. Am. Chem. Soc. 2011, 133, 20901. (b) Lishchynskyi, A.; Novikov, M. A.; Escudero-Adan, E. C.; Novak, P.; Grushin, V. V.J. Org. Chem. 2013, 78, 11126.

(4) (a) Surya Prakash, G. K.; Yudin, A. K. Chem. Rev. 1997, 97, 757. (b) Ma, J.-A.; Cahard, D. Chem. Rev. 2008, 108, PR1.

(5) Kawai, H.; Yuan, Z.; Tokunaga, E.; Shibata, N. Org. Biomol. Chem. 2013, 11, 1446.
(6) Thomson, C. S.; Dolbier, W. R. Jr J. Org. Chem. 2013, 78, 8904.

(7) Iida, T.; Hashimoto, R.; Aikawa, K.; Ito, S.; Mikami, K. Angew. Chem. Int. Ed. 2012, 51, 9535.

(8) Zhang, Y.; Fujiu, M.; Serizawa, H.; Mikami, K. J. Fluorine Chem. 2013, 156, 367.

(9) Novak, P.; Lishchynskyi, A.; Grushin, V. V. Angew. Chem. Int. Ed. 2012, 51, 7767.

(10) Novak, P.; Lishchynskyi, A.; Grushin, V. V.J. Am. Chem. Soc. 2012, $134,16167$.

(11) Potash, S.; Rozen, S. J. Org. Chem. 2014, 79, 11205. 